\title{
Degraded lands worth protecting: the biological importance of Southeast Asia's repeatedly logged forests
}

\author{
David P. Edwards ${ }^{1}, *$, Trond H. Larsen ${ }^{2}$, Teegan D. S. Docherty ${ }^{1}$, \\ Felicity A. Ansell ${ }^{1}$, Wayne W. Hsu ${ }^{3}$, Mia A. Derhé ${ }^{4}$, Keith C. Hamer ${ }^{1}$ \\ and David S. Wilcove ${ }^{2}$ \\ ${ }^{1}$ Institute of Integrative and Comparative Biology, University of Leeds, Leeds LS2 9fT, UK \\ ${ }^{2}$ Woodrow Wilson School and Department of Ecology and Evolutionary Biology, Princeton University, \\ Princeton, NF 08544, USA \\ ${ }^{3}$ Department of Ecology, Evolution, and Environmental Biology, Columbia University, New York, \\ NY 10027, USA \\ ${ }^{4}$ School of Biological Sciences, University of East Anglia, Norwich NR4 7TF, UK
}

\begin{abstract}
Southeast Asia is a hotspot of imperilled biodiversity, owing to extensive logging and forest conversion to oil palm agriculture. The degraded forests that remain after multiple rounds of intensive logging are often assumed to be of little conservation value; consequently, there has been no concerted effort to prevent them from being converted to oil palm. However, no study has quantified the biodiversity of repeatedly logged forests. We compare the species richness and composition of birds and dung beetles within unlogged (primary), once-logged and twice-logged forests in Sabah, Borneo. Logging had little effect on the overall richness of birds. Dung beetle richness declined following once-logging but did not decline further after twice-logging. The species composition of bird and dung beetle communities was altered, particularly after the second logging rotation, but globally imperilled bird species (IUCN Red List) did not decline further after twice-logging. Remarkably, over 75 per cent of bird and dung beetle species found in unlogged forest persisted within twice-logged forest. Although twice-logged forests have less biological value than primary and once-logged forests, they clearly provide important habitat for numerous bird and dung beetle species. Preventing these degraded forests from being converted to oil palm should be a priority of policy-makers and conservationists.
\end{abstract}

Keywords: biodiversity; landscape planning; oil palm; secondary forest; selective logging

\section{INTRODUCTION}

Southeast Asia is widely regarded as one of the hottest of the world's hotspots of imperilled biodiversity [1-3]. This recognition stems from the fact that most of Southeast Asia's rainforests have been logged or converted to agricultural uses such as oil palm plantations (e.g. [4]). The rate of deforestation in Southeast Asia exceeds that of most other tropical regions, as does the rate of timber extraction [3,5]. Indeed timber exports from Borneo alone surpass those from all of tropical Africa and Latin America combined [6]. Most of the remaining forest in Southeast Asia is classified as production forest [7] and therefore is open to logging.

In most cases, selective logging is used. 'Selective', however, is something of a misnomer: in Southeast Asia's dipterocarp forests, virtually all of the large, marketable trees are typically removed, leaving only the smaller or less desirable ones. Depending on market demand and other factors, most trees remaining after the first logging rotation may be harvested less than 20 years later [8],

* Author for correspondence (d.p.edwards@leeds.ac.uk).

Electronic supplementary material is available at http://dx.doi.org/10. 1098/rspb.2010.1062 or via http://rspb.royalsocietypublishing.org. leaving behind a highly degraded forest. Such degraded forests exhibit dramatically altered structure, with a low, open canopy and high density of climbing vines and bamboos (D. Edwards 2007-2009, unpublished data).

The forests that remain after logging are vulnerable to conversion to oil palm, which is now the principal factor driving the loss of lowland forest in Southeast Asia [3,9]. Indeed, at least 55 per cent of the expansion of oil palm between 1990 and 2005 in Malaysia and Indonesia occurred at the expense of rainforest (both logged and unlogged forest [10]). Pressure from environmentalists has caused palm oil producers and governmental agencies in Malaysia, Indonesia and other Southeast Asian nations to restrict the conversion of primary (unlogged) forests to oil palm. But intensively logged forests are more vulnerable, especially those that are perceived to be highly degraded. For example, the Chief Executive Officer of the Malaysian Palm Oil Council (MPOC) has written, '...[T] here are still opportunities in Sarawak and other parts of Malaysia to develop degraded logged over land for planting oil palm and rubber to increase the country's sources of foreign exchange while avoiding deforestation of its pristine permanent forests' (http:// ceopalmoil.blogspot.com/2008/11/creating-fine-balancefor-development.html), while the World Resources 
Institute, an international environmental organization, condones the conversion of Indonesia's 15-20 million hectares of degraded lands, including logged forests, to oil palm, albeit in a bid to reduce the rate of conversion of primary forests [11].

Governments and non-profit organizations must decide where to allocate scarce resources-financial and political - for conservation. In Southeast Asia, the choices are relatively straightforward at the extremes: the value of primary forests for biodiversity is undisputed, while oil palm plantations harbour just a fifth of the bird species found in primary forest and few, if any, species of conservation concern $[12,13]$. However, as noted earlier, very few of Southeast Asia's forests are likely to escape logging. A critical question therefore is the degree to which logging diminishes biodiversity. In other words, does a heavily logged forest become a biological wasteland?

Previous studies from Southeast Asia and other tropical regions have shown that selective logging has limited effects on species richness and diversity across a range of taxa, including birds and dung beetles [14-17]. Thus, a general consensus has developed that forests subjected to selective logging retain much of their value for biodiversity. However, all of these studies have focused on the first rotation of selective logging. In Southeast Asia, it is the premature re-entry into these areas for a second rotation of logging that takes away most of the remaining large- and medium-diameter trees, causes further residual damage, sharply reduces the future timber value of the site and increases the probability that an area will be classified as degraded. It is therefore critical to evaluate the biodiversity value of selectively logged rainforests that have undergone a second rotation $[18,19]$.

In this study, we examine the effects of a second logging cycle on biodiversity, and we do so by focusing on bird and dung beetle communities in Bornean rainforests. Birds and dung beetles are the most cost-effective indicator taxa in biodiversity surveys [20], and, among invertebrates, dung beetles are particularly important ecologically and are tightly linked with mammal communities [21]. We compare bird and dung beetle communities in unlogged (UL) forest, first rotation (once-logged; 1L) forest, and second rotation (twicelogged; 2L) forest. We examine differences in species richness and composition, as well as population-level responses for the whole community and for species of conservation concern, using standardized point count, mist net censuses and pitfall traps.

\section{METHODS}

\section{(a) Study site}

The 1 million hectare Yayasan Sabah (YS) logging concession, located in Sabah, Malaysia, is one of the largest and biologically most significant areas of lowland dry dipterocarp forest remaining in Borneo [22]. Forests are dominated numerically by large tree species in the family Dipterocarpaceae [23], most of which are valuable for timber. Fieldwork was conducted in the 238000 ha Ulu Segama-Malua Forest Reserve (US-MFR), which is situated within the YS concession. The US-MFR was selectively logged between 1976 and 1991 following a modified uniform system [24] in which all commercially valuable trees of more than
$0.6 \mathrm{~m}$ diameter were removed using tractors and high-lead cable extraction techniques. This resulted in approximately $120 \mathrm{~m}^{3}$ (range: $73-166 \mathrm{~m}^{3}$ ) of timber extracted per hectare [25]. During the second rotation, 141000 ha (approx. $60 \%$ ) of the US-MFR was relogged between 2001 and 2007. Extraction again followed a modified uniform system, but the minimum tree diameter was reduced to more than or equal to $0.4 \mathrm{~m}$ for commercial species and, in some areas, pioneer trees with diameter more than or equal to $0.25 \mathrm{~m}$ were also cut. This second rotation resulted in an additional $15-72 \mathrm{~m}^{3}$ of timber extracted per ha (Yayasan Sabah 2009, unpublished data).

Selectively logged forest in the US-MFR is contiguous with the 45200 ha Danum Valley Conservation Area (DVCA) and Palum Tambun Watershed Reserve, and approximately $30 \mathrm{~km}$ from the 28000 ha Tawau Hills National Park, which contains unlogged (primary) forest.

\section{(b) Sampling}

Fieldwork was conducted from July to October 2007, May to August 2008 and May to October 2009. Eighteen sites were established within the unlogged, once-logged and twicelogged forest matrix, comprising six sites spread across two replicate patches of each forest type (figure 1). Our study taxa were sampled in a subset of these sites ( $n_{\text {birds: point }}$ counts $=12 ; n_{\text {birds: } \text { mist nets }}=18 ; n_{\text {dung beetles }}=9$ ), which were divided equally among the forest types. Sites within each habitat were located more than or equal to $2 \mathrm{~km}$ apart, with 1-90 km between sites in different forest types. Once-logged forest sites had been logged between 1987 and 1991, and twice-logged sites were logged between 2001 and 2007, and sampled more than 1 year after the cessation of logging. Sampling took place during the relatively dry period of the year, and all three sampling years were similar in terms of environmental conditions (no mast-fruiting, droughts or floods). Moreover, within each taxon, all three habitats were sampled in the same year(s).

\section{(i) Avifauna}

We used two sampling techniques: point counts (2008 and 2009) and mist nets (2007, 2008 and 2009). Studies in tropical forests have indicated that census points separated by more than $200 \mathrm{~m}$ are statistically independent ([26,27]; see also [17]) and, in our study, only 6 of 2545 individuals (less than $0.01 \%$ ) were captured on more than one mist netting transect.

\section{(ii) Point counts}

Birds were sampled using unlimited-radius point counts (see [12] for details). At four sites within each forest type, 12 count stations were established at $250 \mathrm{~m}$ intervals (144 stations in total), and each station was visited for $15 \mathrm{~min}$ on three consecutive days. Given that many tropical birds show high site fidelity, the final count for a particular species at a station was taken as the highest number of individuals recorded on any of the three visits.

\section{(iii) Mist nets}

We used mist netting to survey the cryptic lower-storey birds that can be under-sampled by point counts [28] and to provide an independent assessment of the effects of logging on this subset of the bird community. At each site, we erected 15 mist nets along two transects positioned $500-800 \mathrm{~m}$ apart and nets were opened from $06.00-12.00$ on three consecutive days (see [29] for details; 9720 mist net hours in 


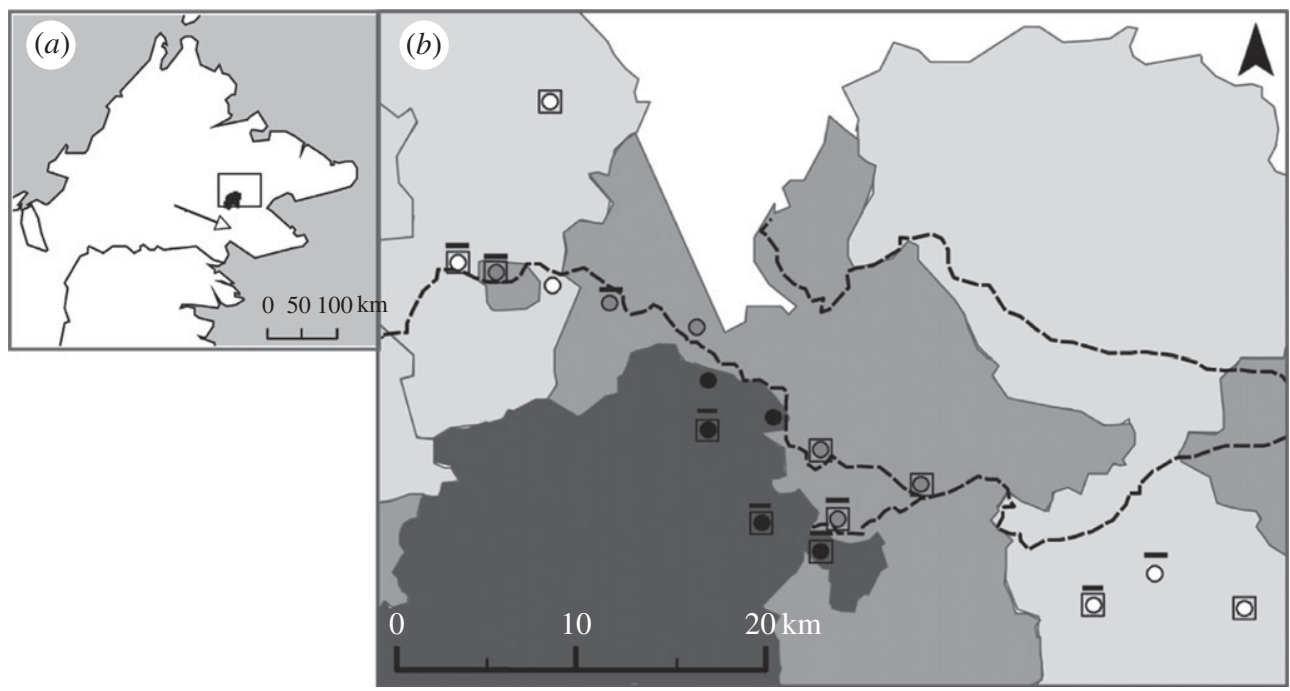

Figure 1. (a) Map of Sabah, Malaysian Borneo. The black region represents the Danum Valley Conservation Area (DVCA) and the arrow indicates a mist net and point count site at Tawau Hills National Park. (b) Map of the study area within the Yayasan Sabah (YS) logging concession. Circles indicate mist net sites, squares indicate point count sites, and black horizontal bars indicate pitfall trapping sites. Shading: dark grey, unlogged forest (DVCA); medium grey, once-logged forest; pale grey, twice-logged forest; white, oil palm outside the YS concession.

total). Because the canopy of degraded forests is lower than in unlogged forests, canopy species are likely to forage lower and be more susceptible to capture in mist nets [30]. We therefore restricted our analysis to species that are not defined as canopy specialists $(n=33$ individuals of 14 species removed [31]).

\section{(iv) Dung beetles}

We used standardized pitfall traps baited with human dung (see [32] for details) to sample dung beetles (Coleoptera: Scarabaeidae: Scarabaeinae) in 2009. Human dung is the most effective bait and attracts virtually all dung-feeding species [15,33]. At each of three sites within each forest category, we set 10 traps spaced at $100 \mathrm{~m}$ intervals (90 traps in total). Trap spacing should be sufficient for independence among traps [32]. Traps were collected every $24 \mathrm{~h}$ for four days and were rebaited after two days. Species determinations were made by T. Larsen, W. Hsu and D. Mann (Oxford University, Museum of Natural History). Voucher specimens are deposited in the private collection of A. Forsyth at the National Museum of Natural History, Smithsonian Institution, Washington DC, USA, and at the Forest Research Center, Sandakan, Malaysia.

\section{(c) Data analyses}

(i) Species richness

Patterns of overall species richness were compared among forest types using sample-based rarefaction curves with 95 per cent CI, constructed in EstimateS v. 8.2 (University of Connecticut, Storrs, CT). Species richness is highly sensitive to sample size and accumulation curves were standardized by the total number of individuals sampled in each forest type [34]. To estimate the probable species pool in each forest type and assess the completeness of our faunal surveys, we calculated the mean of four commonly used abundancebased species richness estimators (ACE, CHAO1, JACK1, and BOOTSTRAP; see [29]) using EstimateS v. 8.2. To control for any confounding effects of the spatial scale at which data were analysed [17], we also compared species richness ( $\alpha$-diversity) between forest types at the level of individual sample points and using combined data for each site, using generalized linear models (GLZs) with Poisson error and a log link in GLMSTAT v. 5.7.7. In addition, we compared rates of species turnover among sample points and sites within each forest type ( $\beta$-diversity, calculated using Whittaker's index (w) [35]) using Species Diversity AND Richness v. 2.65 (PISCES Conservation Ltd., Oxford).

\section{(ii) Species composition}

In order to determine how patterns of species make-up differed among unlogged, once-logged and twice-logged forests, we examined species-abundance matrices using CAP v. 3.1 (PISCES Conservation Ltd., Oxford). Matrices were square-root transformed to reduce the effect of the commonest species. Ordination of transects according to species similarity (Bray-Curtis index [35]) was then achieved using non-metric multi-dimensional scaling (MDS [36]), and we tested for differences among forest types using an analysis of similarity (ANOSIM). We repeated all ordination analyses using presence-absence data to compare patterns of species composition independently of abundance, but these analyses yielded qualitatively similar results to those using species-abundance matrices, and so only the latter are presented.

Additionally, focusing on all International Union for Conservation of Nature (IUCN) Red-Listed bird species (classified as near-threatened or vulnerable [37]) recorded in the study, we compared the overall shift in abundance and species richness per transect following one and two rotations of logging, using GLZs with Poisson error and a $\log$ link in GLMSTAT v. 5.7.7. Dung beetles for this region have not thus far been classified by the IUCN.

\section{(iii) Population-level responses}

In order to ascertain which species were susceptible to logging and which benefited from logging, we compared the abundance of each species in unlogged forest with its abundance in once- and in twice-logged forests using GLZs with Poisson error and a log link in R STAT v. 2.8.1. 

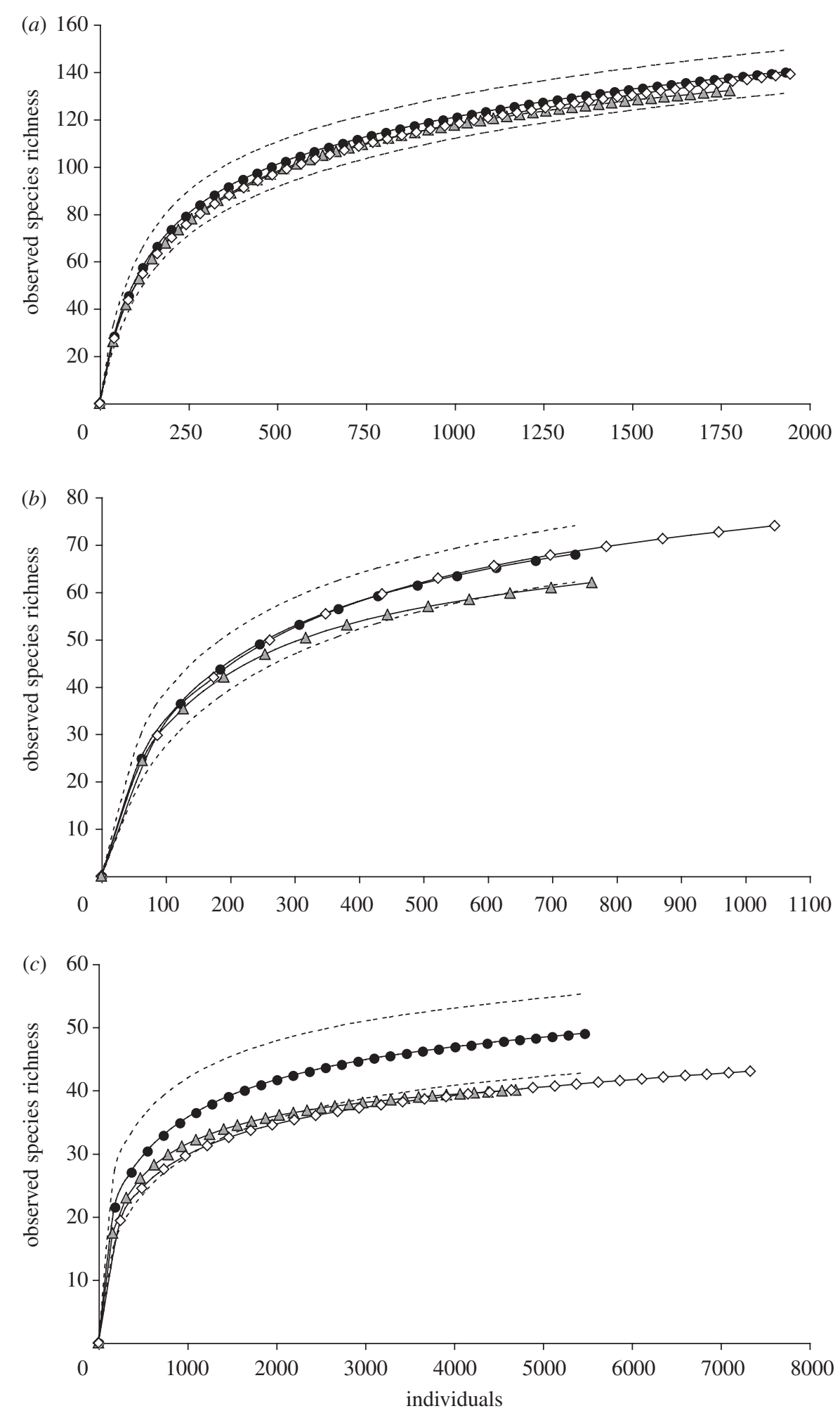

Figure 2. Observed species richness, constructed using sample-based rarefaction curves for the three forest types. (a) All birds, (b) understorey birds and $(c)$ dung beetles. The $x$-axis is scaled to show the number of individuals and scales differ between figures. Black circle, unlogged; grey triangle, once-logged; white diamond, twice-logged; dotted lines, 95\% CI for unlogged forest.

\section{RESULTS}

\section{(a) Species richness}

We recorded 5654 individuals of 179 bird species with point counts (herein termed 'all birds') and 2545 individuals of 89 species with mist netting (herein termed 'understorey birds'). Mist nets added eight species not recorded from point counts. There was no difference in total species richness between unlogged, once-logged and twice-logged forests for all birds nor for understorey birds (figure $2 a, b$; table 1 ). At the scale of individual sampling points, species richness did not differ between forest types for all birds (GLZ: $p=0.2$ ). In contrast, for understorey birds there was a significant shift in species richness $\left(\chi^{2}=13.0, p=0.0015\right)$, which increased in twice-logged forest compared with unlogged $(p=0.03)$ and once-logged $(p=0.01)$ forests, but no difference 


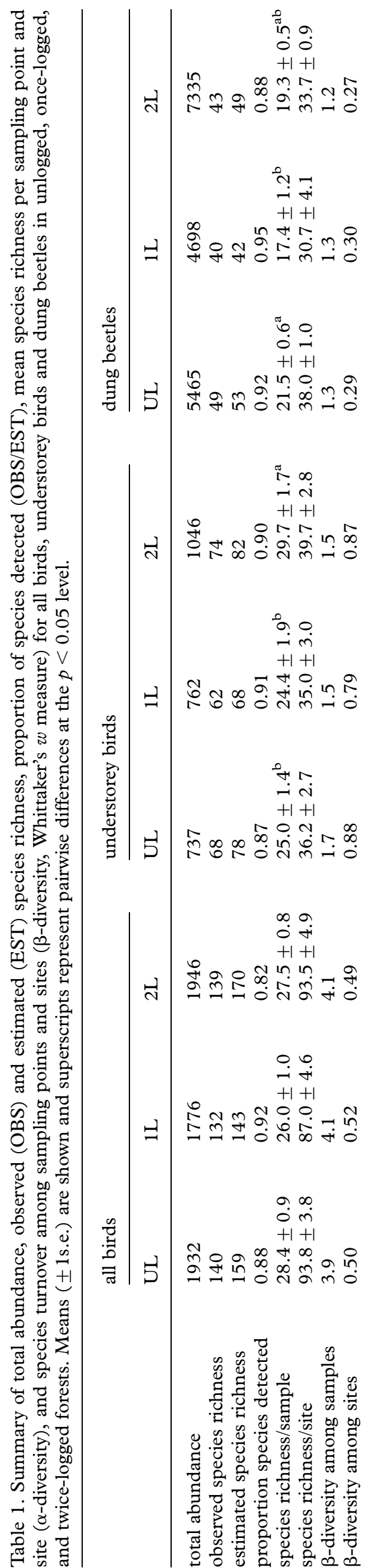

between unlogged and once-logged forests $(p=0.8)$. There was no effect of logging on $\beta$-diversity between sampling points. At the site level, there was no difference in species richness between forest types (all birds, $p=0.5$; understorey birds, $p=0.4$ ) nor in $\beta$-diversity after a second logging rotation (table 1), indicating limited effects of spatial scale.

We sampled 17498 individuals of 53 dung beetle species in pitfall traps. Total species richness for dung beetles declined by 18 per cent in once-logged forests and by 12 per cent in twice-logged forests (figure $2 c$; table 1). At the scale of individual traps, there was a significant shift in species richness (GLZ: $\chi^{2}=13.0$, $p=0.0015)$, which declined in once-logged ( $p=$ 0.0003 ) and (marginally so) in twice-logged ( $p=$ 0.06) forests compared with unlogged forest, but did not differ between the logged forest types $(p=0.1)$. There was no effect of logging on $\beta$-diversity among traps (table 1). At the site level, there was no reduction in species richness $(p=0.3)$ or $\beta$-diversity following logging (table 1).

Resampling the data with four abundance-based estimators of species richness suggests that our observed patterns of species richness are reliable, indicating that our censuses sampled between 82 and 92 per cent completeness of birds, and between 88 and 95 per cent of dung beetles (table 1).

\section{(b) Species composition}

Patterns of species abundance differed significantly among forest types for all birds (figure 3a; ANOSIM: $r=$ $0.56, p=0.001$ ), for understorey birds (figure $3 b$; $r=0.40, p=0.001$ ) and for dung beetles (figure $3 c$; $r=0.18, p=0.005)$. Pairwise comparisons for avian analyses revealed that species assemblages were significantly different between all habitats $(p \leq 0.03)$, with the exception of unlogged and once-logged forest for all birds $(p=0.07)$. For dung beetles, unlogged and second rotation assemblages were marginally different $(p=0.05)$, while other habitat pairs did not differ significantly $(p \geq 0.15)$.

We then focused on every Red-Listed bird species recorded in the study, and found significant variation in the overall abundance (figure $4 a$; all birds, $\chi^{2}=41.0$, $p<0.0001$; understorey birds, $\chi^{2}=10.6, p<0.0050$ ) and species richness (figure $4 b$; all birds, $\chi^{2}=25.2$, $p<0.0001$ ) between forest types. Post hoc tests of point count data revealed that abundance and species richness of Red-Listed species were lower in oncelogged and twice-logged forests than in primary forests; however, there was no significant difference between the logged forest types. In contrast, Red List birds sampled via mist nets exhibited similar abundance in primary and twice-logged forests, but markedly lower abundance in once-logged forests. Species richness of Red-Listed species sampled with mist nets did not differ between forest types (figure $4 b$; understorey birds, $\chi^{2}=2.9, p=0.23$ ).

\section{(c) Population-level responses}

Ninety-six species (54\%) of all birds, 45 species (51\%) of understorey birds and 26 species (49\%) of dung beetles revealed at least one significant change in abundance 

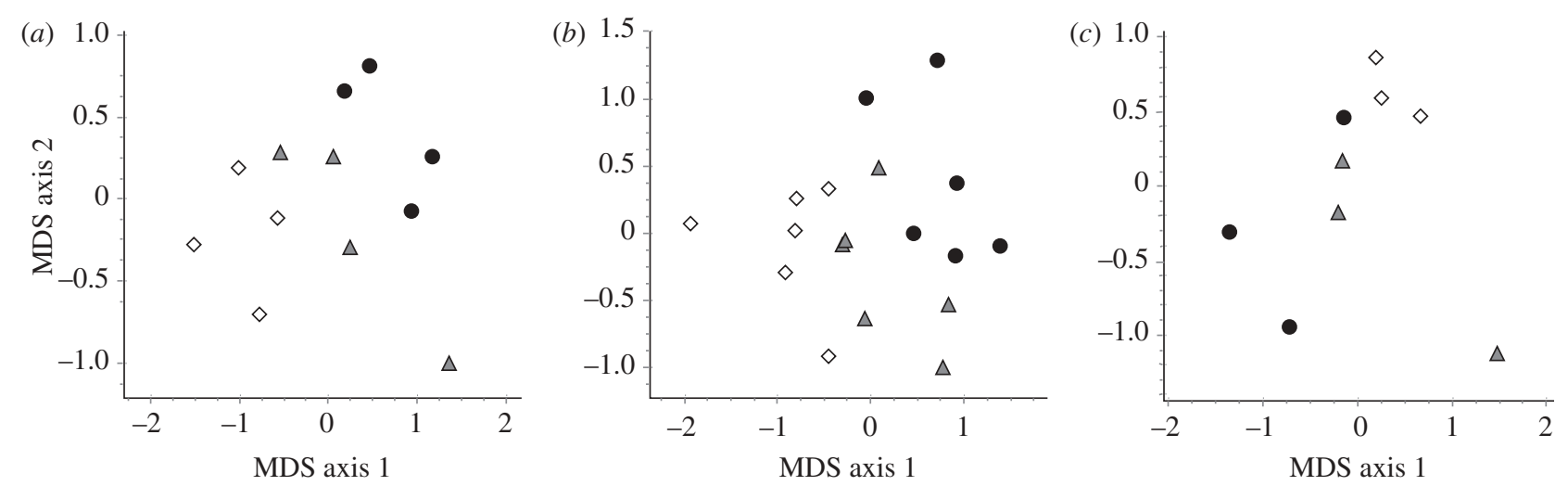

Figure 3. Non-metric multidimensional scaling (MDS) ordination of community structure among unlogged (black circle), once-logged (grey triangle) and twice-logged (open diamond) forest types. (a) All birds (stress $=0.08$ ), $(b)$ understorey birds (stress $=0.15)$ and $(c)$ dung beetles (stress $=0.08)$.
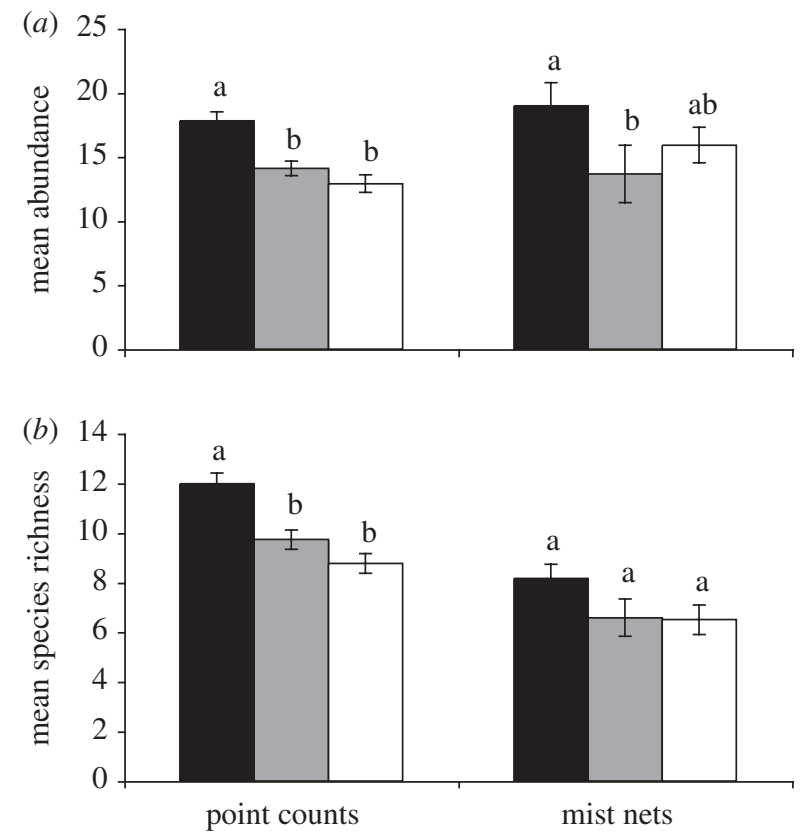

Figure 4. The prevalence of Red-Listed birds (Birdlife International 2009) in unlogged (black bar), once-logged (grey bar) and twice-logged (white bar) forest. (a) Mean abundance and (b) mean species richness. Letters denote significant differences at the $p<0.001$ level using pairwise comparisons.

following logging (see the electronic supplementary material, tables S1 and S2). Both logged and unlogged forests held unique species (see the electronic supplementary material, tables $\mathrm{S} 1$ and S2): 38 species of all birds $\left(21 \% ; n_{\text {once-logged }}=19 ; n_{\text {twice-logged }}=33\right), 21$ species of understorey birds $\left(24 \% ; n_{\text {once-logged }}=9 ; n_{\text {twice-logged }}=19\right)$, and 4 species of dung beetles $\left(7.5 \% ; n_{\text {once-logged }}=1\right.$; $n_{\text {twice-logged }}=4$ ) occurred only in logged forests, while 13 species $(7 \%)$ of all birds, 5 species $(6 \%)$ of understorey birds and 6 species (11\%) of dung beetles were present only in unlogged forest.

Focusing on those species that were recorded in unlogged forest, birds ( $n_{\text {all birds }}=140 ; n_{\text {understorey birds }}=$ 68 ) and dung beetles $(n=49)$ responded in a similar way to logging rotations (figure 5; see also the electronic supplementary material, tables S1 and S2). For all birds and understorey birds, about 30 per cent of species

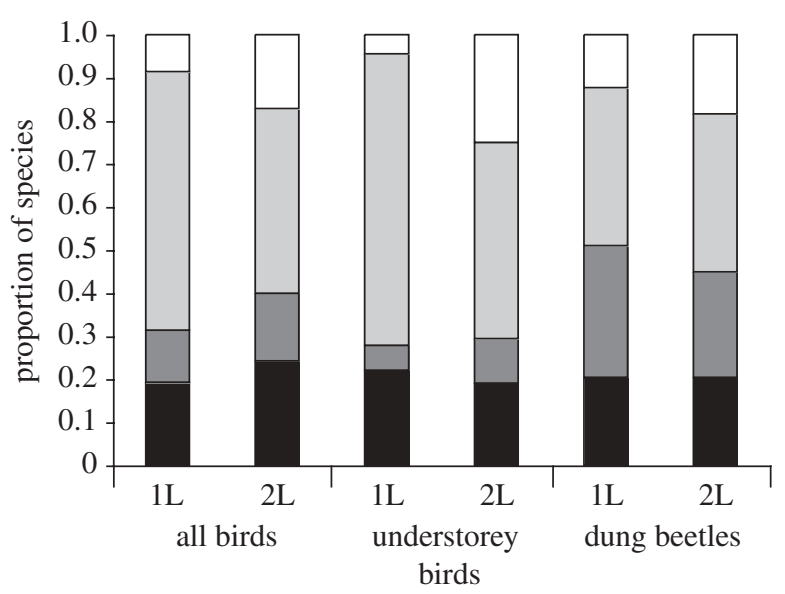

Figure 5. Population-level responses of bird and dung beetle species to two logging rotations. The percentage of species recorded in unlogged forest that were absent (black), declined significantly (dark grey), revealed no significant change (light grey) and increased significantly (white) following once-logging $(1 \mathrm{~L})$ and twice-logging $(2 \mathrm{~L})$.

were either lost or significantly declined in abundance following the first logging rotation, but there was no further decline after the second rotation (figure 5). For dung beetles, about half of the species were either lost or declined significantly following the first rotation and there was a marginal recovery in the level of species decline after the second rotation (figure 5). However, despite species loss and declines, over 75 per cent of bird and dung beetle species from unlogged forest persisted within twice-logged forest.

We then focus on only those species recorded in unlogged forest that were endemic to Borneo. We find that no endemic bird species was affected by the first rotation of logging. However, 55 per cent (five species) of endemic birds sampled via point counts and 29 per cent (two species) of endemic birds sampled via mist nests disappeared or declined in abundance after the second rotation (see the electronic supplementary material, table $\mathrm{S} 1$ ). In contrast, 47 per cent of the dung beetle species endemic to Borneo $(n=15)$ declined after the first rotation, but there was a marginal recovery after the second rotation, with 40 per cent of endemic 
species declining from unlogged forest levels (see the electronic supplementary material, table S2).

\section{DISCUSSION}

This is the first study to investigate the effects of multiple logging rotations on biodiversity in Southeast Asia. In our study area, virtually all commercially valuable trees (more than or equal to $40 \mathrm{~cm}$ in diameter) were removed during the second rotation, and the logging practices used have been shown to result in high levels of residual damage (e.g. [7]). While the first rotation caused some bird and dung beetle species to decline or disappear (table 1; figure 5), it is the second logging rotation that more strongly affected species composition (figure 3) and caused a number of bird species endemic to Borneo to decline (see the electronic supplementary material, table $\mathrm{S} 1$ ). Thus, logging clearly is harmful to some species and this harm is magnified by a second round of logging.

Notwithstanding these declines, and despite the very intensive logging in our study area after the second rotation, over 75 per cent of bird and dung beetle species from unlogged forest persisted within twice-logged forest, and these included a striking number of imperilled (RedListed) bird species (figure 4). Furthermore, there was no negative impact of logging on bird species richness or $\beta$-diversity (figure 2 ; table 1 ) and, while dung beetles appeared to be more sensitive than birds (showing a decline in species richness following the first rotation), they revealed no further decline after the second rotation and no difference in $\beta$-diversity. Far from being of little conservation value, therefore, the twice-logged forests harbour surprisingly rich bird and dung beetle communities, including a number of species of conservation concern.

Since our sampling protocol used different combinations of sites for different taxa (figure 1), we reanalysed our data for understorey birds using only the nine sites censused for dung beetles. This made no major qualitative difference to our species richness and composition results (see the electronic supplementary material, SOM text S1), indicating that our use of different sites was unlikely to have altered our conclusions with respect to the effects of logging rotations on different taxa. Research into the effects of the second logging rotation on other taxa is now vital for a fuller understanding of the value of degraded forest for biodiversity. However, since birds and dung beetles are reasonable indicators of general patterns across taxa $[14,38,39]$, our results can probably be extrapolated to other taxa.

We cannot be certain that the populations of species in twice-logged forests are not in extinction debt, especially in the case of birds, which are generally longer-lived than beetles. Resolving that question would require a longterm study of reproductive success in degraded forest. However, we found high densities of many bird species at the twice-logged sites (see the electronic supplementary material, table S1), including singing individuals holding territories and family parties with juvenile individuals (D. Edwards 2007-2009, personal observation). Some juveniles may have dispersed into degraded forests from other forest types to exploit lower densities of breeding birds defending territories [40], but our data nonetheless suggest that there was successful recruitment within twice-logged forest. Furthermore, those bird species that had declined in abundance a few years after the first logging rotation [41] had either recovered or managed to persist at reduced abundance after $12-20$ years of regeneration (see the electronic supplementary material, table $\mathrm{S} 1$; see [23] for data 12 years post-logging). This suggests that susceptible species are not moving inexorably towards extinction in the years after logging.

Another important unknown is the successional trajectory of degraded forest. If a diversity of native trees is able to regenerate naturally (e.g. [42]), then we would predict that the value of these forests for sensitive birds and dung beetles will only increase over time [43]. If, however, tree regeneration is stalled by the growth of vines and lianas, then taxa of conservation concern could conceivably remain at depressed levels or even decline further if a sizeable fraction of the remaining trees die or are damaged owing to edge effects, fire, etc. [44,45].

Given predictions that all of Borneo's forests outside protected areas will have been logged at least once by 2010 [46] and that many of these logged forests will undergo an early and intensive second cut [8], our results have both negative and positive implications for conservation. On the negative side, an early and intensive second cut reduces the persistence of some bird and dung beetle species within the remaining degraded forests. Of particular concern are those Red-Listed bird species and sensitive dung beetle species that appear to have gone locally extinct within these lands, and we do not yet know whether these species will be able to recolonize from sources within once-logged or unlogged forests. Given these current biodiversity costs, as well as other possible longer-term issues such as fire risk [47] and altered trophic dynamics (e.g. [48]), a strong case can be made against allowing early re-entry into once-logged forests.

On the positive side, however, it is clear that a substantial proportion of Borneo's bird and dung beetle fauna, and presumably other groups of organisms as well, do persist in forests that have already undergone a recent second round of logging and that are now exceptionally degraded in structure. The ability of most species to persist in such sites reduces their risk of extinction and indicates that these degraded forests provide important habitat for biodiversity conservation at the metapopulation level. Furthermore, these degraded forests have far higher overall bird species richness, as well as a twohundred-fold higher abundance of Red-Listed bird species, than the oil palm that threatens to replace them [12]. Preventing them from being converted to oil palm and other crops should thus be an urgent priority of policy makers and conservationists in Southeast Asia.

We thank David Andrews, Takahiro Ota, Leah Williams and Simon Mitchell for assistance with fieldwork, Darren Mann and Eleanor Slade for providing reference collections and support with determinations, Glen Reynolds, the Royal Society's SEARRP and the Borneo Rainforest Lodge for logistical support, Arthur Chung and Abdul Ahmad for collaborative support, and three anonymous referees for comments. We also thank Yayasan Sabah, Danum Valley Management Committee, Sabah Parks, the State Secretary, Sabah Chief Minister's Departments and the Economic Planning Unit of the Prime Minister's Department for permission to conduct research. D.P.E. was supported by a Leverhulme Trust research grant and T.H.L. by a 
fellowship from World Wide Fund for Nature. Additional support was provided by a grant from the High Meadows Foundation to D.S.W.

\section{REFERENCES}

1 Butchart, S. H. M., Stattersfield, A. J., Bennun, L. A., Shutes, S. M., Akcakaya, H. R., Baillie, J. E. M., Stuart, S. N., Hilton-Taylor, C. \& Mace, G. M. 2004 Measuring global trends in the status of biodiversity: Red List indices for birds. Plos Biol. 2, 2294-2304.

2 Myers, N., Mittermeier, R. A., Mittermeier, C. G., da Fonseca, G. A. B. \& Kent, J. 2000 Biodiversity hotspots for conservation priorities. Nature 403, 853-858. (doi:10.1038/35002501)

3 Sodhi, N. S., Koh, L. P., Brook, B. W. \& Ng, P. K. L. 2004 Southeast Asian biodiversity: an impending disaster. Trends Ecol. Evol. 19, 654-660. (doi:10.1016/j.tree. 2004.09.006)

4 Curran, L. M., Trigg, S. N., McDonald, A. K., Astiani, D., Hardiono, Y. M., Siregar, P., Caniago, I. \& Kasischke, E. 2004 Lowland forest loss in protected areas of Indonesian Borneo. Science 303, 1000-1003. (doi:10. 1126/science.1091714)

5 Hansen, M. C. et al. 2008 Humid tropical forest clearing from 2000 to 2005 quantified by using multitemporal and multiresolution remotely sensed data. Proc. Natl Acad. Sci. USA 105, 9439-9444. (doi:10.1073/pnas. 0804042105)

6 Cleary, D. F. R., Boyle, T. J. B., Setyawati, T., Anggraeni, C. D., Van Loon, E. E. \& Menken, S. B. J. 2007 Bird species and traits associated with logged and unlogged forest in Borneo. Ecol. Appl. 17, 1184-1197. (doi:10. 1890/05-0878)

7 Johns, A. G. 1997 Timber production and biodiversity conservation in tropical rain forests. Cambridge, UK: Cambridge University Press.

8 van Gardingen, P. R., McLeish, M. J., Phillips, P. D., Fadilah, D., Tyrie, G. \& Yasman, I. 2003 Financial and ecological analysis of management options for logged-over Dipterocarp forests in Indonesian Borneo. Forest Ecol. Manage. 183, 1-29. (doi:10.1016/S03781127(03)00097-5)

9 Stibig, H. J. \& Malingreau, J. P. 2003 Forest cover of insular Southeast Asia mapped from recent satellite images of coarse spatial resolution. Ambio 32, 469-475.

10 Koh, L. P. \& Wilcove, D. S. 2008 Is oil palm agriculture really destroying tropical biodiversity? Conserv. Lett. 1, 60-64. (doi:10.1111/j.1755-263X.2008.00011.x)

11 WRI (World Resources Institute) 2009. Project POTICO: palm oil, timber \& carbon offsets in Indonesia. See http://www.wri.org/project/potico.

12 Edwards, D. P., Hodgson, J. A., Hamer, K. C., Mitchell, S. L., Ahmad, A. H., Cornell, S. J. \& Wilcove, D. S. 2010 Wildlife-friendly oil palm plantations fail to protect biodiversity effectively. Conserv. Lett. (doi:10.1111/j. 1755-263X.2010.00107.x)

13 Peh, K. S. H., Sodhi, N. S., de Jong, J., Sekercioglu, C. H., Yap, C. A. M. \& Lim, S. L. H. 2006 Conservation value of degraded habitats for forest birds in southern Peninsular Malaysia. Divers. Distrib. 12, 572-581. (doi:10.1111/j.1366-9516.2006.00257.x)

14 Berry, N. J. et al. 2010 The high value of logged tropical forests: lessons from northern Borneo. Biodivers. Conserv. 19, 985-997. (doi:10.1007/s10531-010-9779-z)

15 Davis, A. J., Holloway, J. D., Huijbregts, H., Krikken, J., Kirk-Spriggs, A. H. \& Sutton, S. L. 2001 Dung beetles as indicators of change in the forests of northern Borneo. F. Appl. Ecol. 38, 593-616. (doi:10.1046/j.1365-2664. 2001.00619.x)
16 Dent, D. H. \& Wright, S. J. 2009 The future of tropical species in secondary forests: a quantitative review. Biol. Conserv. 142, 2833-2843. (doi:10.1016/j.biocon.2009. 05.035)

17 Hill, J. K. \& Hamer, K. C. 2004 Determining impacts of habitat modification on diversity of tropical forest fauna: the importance of spatial scale. F. Appl. Ecol. 41, 744-754. (doi:10.1111/j.0021-8901.2004.00926.x)

18 Bawa, K. S. \& Seidler, R. S. 1998 Natural forest management and conservation of biodiversity in tropical forests. Conserv. Biol. 12, 46-55. (doi:10.1046/j.15231739.1998.96480.x)

19 Willott, S. J., Lim, D. C., Compton, S. G. \& Sutton, S. L. 2000 Effects of selective logging on butterflies of a Bornean rainforest. Conserv. Biol. 14, 1055-1065. (doi:10.1046/j.1523-1739.2000.98427.x)

20 Gardner, T. A. et al. 2008 The cost-effectiveness of biodiversity surveys in tropical forests. Ecol. Lett. 11, 139-150.

21 Nichols, E., Spector, S., Louzada, J., Larsen, T., Amequita, S. \& Favila, M. E. 2008 Ecological functions and ecosystem services provided by Scarabaeinae dung beetles. Biol. Conserv. 141, 1461-1474. (doi:10.1016/j. biocon.2008.04.011)

22 Lambert, F. R. \& Collar, N. J. 2002 The future for Sundaic lowland forest birds: long-term effects of commercial logging and fragmentation. Forktail 18, 127-146.

23 Johns, A. G. 1996 Bird population persistence in Sabahan logging concessions. Biol. Conserv. 75, 3-10. (doi:10.1016/0006-3207(95)00044-5)

24 Whitmore, T. C. 1984 Tropical rain forests of the Far East, 2nd edn. Oxford, UK: Clarendon Press.

25 Marsh, C. W. \& Greer, A. G. 1992 Forest land-use in Sabah, Malaysia - an introduction to Danum Valley. Phil. Trans. R. Soc. Lond. B 335, 331-339. (doi:10. 1098/rstb.1992.0025)

26 Pearman, P. B. 2002 The scale of community structure: habitat variation and avian guilds in tropical forest understory. Ecol. Monogr. 72, 19-39. (doi:10.1890/ 0012-9615(2002)072[0019:TSOCSH]2.0.CO;2)

27 Whitman, A. A., Hagan, J. M. \& Brokaw, N. V. L. 1998 Effects of selection logging on birds in northern Belize. Biotropica 30, 449-457. (doi:10.1111/j.1744-7429. 1998.tb00079.x)

28 Blake, J. G. \& Loiselle, B. A. 2001 Bird assemblages in second-growth and old-growth forests, Costa Rica: perspectives from mist nets and point counts. $A u k$ 118, 304-326. (doi:10.1642/0004-8038(2001)118[0304: BAISGA]2.0.CO;2)

29 Edwards, D. P., Ansell, F. A., Ahmad, A. H., Nilus, R. \& Hamer, K. C. 2009 The value of rehabilitating logged rainforest for birds. Conserv. Biol. 23, 1628-1633. (doi:10.1111/j.1523-1739.2009.01330.x)

30 Remsen, J. V. \& Good, D. A. 1996 Misuse of data from mist-net captures to assess relative abundance in bird populations. Auk 113, 381-398.

31 Robson, C. 2000 A field guide to the birds of South-east Asia. London, UK: New Holland Publishers Ltd.

32 Larsen, T. H. \& Forsyth, A. 2005 Trap spacing and transect design for dung beetle biodiversity studies. Biotropica 37, 322-325. (doi:10.1111/j.1744-7429.2005.00042.x)

33 Larsen, T. H., Lopera, A. \& Forsyth, A. 2006 Extreme trophic and habitat specialization by Peruvian dung beetles (Coleoptera: Scarabaeidae: Scarabaeinae). Coleopterists Bull. 60, 315-324. (doi:10.1649/0010065X(2006)60[315:ETAHSB]2.0.CO;2)

34 Gotelli, N. J. \& Colwell, R. K. 2001 Quantifying biodiversity: procedures and pitfalls in the measurement and comparison of species richness. Ecol. Lett. 4, 379-391. (doi:10.1046/j.1461-0248.2001.00230.x) 
35 Magurran, A. E. 2004 Measuring biological diversity. Oxford, UK: Blackwell Science Ltd.

36 Clarke, K. R. \& Warwick, R. M. 2001 Change in marine communities: an approach to statistical analysis and interpretation, 2nd edn. Plymouth, UK: Primer-E.

37 Birdlife International 2010. Species factsheets. See http:// www.birdlife.org.

38 Barlow, J. et al. 2007 Quantifying the biodiversity value of tropical primary, secondary, and plantation forests. Proc. Natl Acad. Sci. USA 104, 18 555-18 560. (doi:10.1073/ pnas.0703333104)

39 Howard, P. C., Viskanic, P., Davenport, T. R. B., Kigenyi, F. W., Baltzer, M., Dickinson, C. J., Lwanga, J. S., Matthews, R. A. \& Balmford, A. 1998 Complementarity and the use of indicator groups for reserve selection in Uganda. Nature 394, 472-475. (doi:10.1038/28843)

40 Anders, A. A., Faaborg, J. \& Thompson, F. R. 1998 Postfledging dispersal, habitat use, and home-range size of juvenile wood thrushes. Auk 115, 349-358.

41 Lambert, F. R. 1992 The consequences of selective logging for Bornean lowland forest birds. Phil. Trans. R. Soc. Lond. B 335, 443-457. (doi:10.1098/rstb.1992.0036)

42 Berry, N. J., Phillips, O. L., Ong, R. C. \& Hamer, K. C. 2008 Impacts of selective logging on tree diversity across a rainforest landscape: the importance of spatial scale. Landscape Ecol. 23, 915-929.

43 Dunn, R. R. 2004 Recovery of faunal communities during tropical forest regeneration. Conserv. Biol. 18, 302-309. (doi:10.1111/j.1523-1739.2004.00151.x)

44 Cochrane, M. A. \& Laurance, W. F. 2002 Fire as a largescale edge effect in Amazonian forests. F. Trop. Ecol. 18, $311-325$.

45 Laurance, W. F. 2000 Do edge effects occur over large spatial scales? Trends Ecol. Evol. 15, 134-135. (doi:10. 1016/S0169-5347(00)01838-3)

46 Hamer, K. C., Hill, J. K., Benedick, S., Mustaffa, N., Sherratt, T. N., Maryati, M. \& Chey, V. K. 2003 Ecology of butterflies in natural and selectively logged forests of northern Borneo: the importance of habitat heterogeneity. F. Appl. Ecol. 40, 150-162. (doi:10.1046/j.13652664.2003.00783.x)

47 Barlow, J. \& Peres, C. A. 2004 Avifaunal responses to single and recurrent wildfires in Amazonian forests. Ecol. Appl. 14, 1358-1373. (doi:10.1890/03-5077)

48 Gray, M. A., Baldauf, S. L., Mayhew, P. J. \& Hill, J. K. 2007 The response of avian feeding guilds to tropical forest disturbance. Conserv. Biol. 21, 133-141. (doi:10. 1111/j.1523-1739.2006.00557.x) 